\title{
The effect of suppressing negative emotions on eating behavior in binge eating disorder.
}

Citation for published version (APA):

Dingemans, A., Martijn, C., Jansen, A. T. M., \& van Furth, E. (2009). The effect of suppressing negative emotions on eating behavior in binge eating disorder. Appetite, 52, 51-57.

https://doi.org/10.1016/j.appet.2008.08.004

Document status and date:

Published: 01/01/2009

DOI:

10.1016/j.appet.2008.08.004

Document Version:

Publisher's PDF, also known as Version of record

Document license:

Taverne

Please check the document version of this publication:

- A submitted manuscript is the version of the article upon submission and before peer-review. There can be important differences between the submitted version and the official published version of record.

People interested in the research are advised to contact the author for the final version of the publication, or visit the DOI to the publisher's website.

- The final author version and the galley proof are versions of the publication after peer review.

- The final published version features the final layout of the paper including the volume, issue and page numbers.

Link to publication

\footnotetext{
General rights rights.

- You may freely distribute the URL identifying the publication in the public portal. please follow below link for the End User Agreement:

www.umlib.nl/taverne-license

Take down policy

If you believe that this document breaches copyright please contact us at:

repository@maastrichtuniversity.nl

providing details and we will investigate your claim.
}

Copyright and moral rights for the publications made accessible in the public portal are retained by the authors and/or other copyright owners and it is a condition of accessing publications that users recognise and abide by the legal requirements associated with these

- Users may download and print one copy of any publication from the public portal for the purpose of private study or research.

- You may not further distribute the material or use it for any profit-making activity or commercial gain

If the publication is distributed under the terms of Article $25 \mathrm{fa}$ of the Dutch Copyright Act, indicated by the "Taverne" license above, 
Research report

\title{
The effect of suppressing negative emotions on eating behavior in binge eating disorder
}

\author{
Alexandra E. Dingemans ${ }^{\text {a,* }}$, Carolien Martijn ${ }^{\mathrm{b}}$, Anita T.M. Jansen ${ }^{\mathrm{b}}$, Eric F. van Furth ${ }^{\mathrm{a}}$ \\ a Center for Eating Disorders 'Ursula', Leidschendam, The Netherlands \\ ${ }^{\mathrm{b}}$ Department of Clinical Psychological Sciences, Maastricht University, Maastricht, The Netherlands
}

\section{A R T I C L E I N F O}

\section{Article history:}

Received 9 June 2008

Received in revised form 7 July 2008

Accepted 1 August 2008

\section{Keywords:}

Binge eating disorder

Negative mood

Emotion regulation

Mood repair

Experiment

Energy depletion

Self-control

Depression

\begin{abstract}
A B S T R A C T
Overeating may be a consequence of the suppression of negative emotions, by depleting self-control resources. This experiment investigated whether (a) there is a causal relationship between the suppression of negative emotions, negative mood, and overeating in people with binge eating disorder (BED) and whether (b) this relationship is increased in depressed people with BED. Sixty-six women with (full and sub-threshold) BED were shown an upsetting movie and then asked either to suppress their emotions or to react naturally. Subsequently, everyone participated in a taste task. After a decline, initial mood before watching the movie was restored after eating. Depressive symptomatology was positively correlated with caloric intake. Within the clinically depressed (Beck Depression Inventory-score $>19$ ) BED group, those who were most affected by the negative mood induction consumed the most calories. No differences were found between the two conditions with regard to caloric intake. No interaction effect was found between depressive symptoms and mood suppression. The hypothesis that suppression of negative emotion leads to overeating in (depressed) binge eaters was not born out. Overeating may serve as a means to (temporary) repair negative mood.
\end{abstract}

(c) 2008 Elsevier Ltd. All rights reserved.

\section{Introduction}

The most prevalent comorbid lifetime diagnosis for individuals with binge eating disorder (BED) is depressive disorder (Dingemans, Spinhoven, \& Van Furth, 2007). Moreover, ample evidence exists that the severity of binge eating is positively related to more severe degrees of depression (Telch \& Agras, 1994). Apart from the findings that BED individuals are relatively more depressed than non-BED individuals, mood states seem especially poor immediately before a binge eating episode (Grilo \& Shiffman, 1994). Binge eater mood states prior to binge eating episodes have also been shown to be more negative than prior to eating events triggered by hunger (Waters, Hill, \& Waller, 2001). Furthermore, binge eating-disordered women experience the hassles of daily life as more stressful than non-BED controls and the greater the stress experienced, the higher the food intake during a binge (Crowther, Shepherd, Sanftner, \& Bonifazi, 2001). In sum, several studies provide evidence that depressive symptoms (trait), acute negative mood (state), and binge eating behavior are related but do not explain the causal relationship between negative affect and binge eating in patients with BED.

\footnotetext{
* Corresponding author at: Center for Eating Disorders 'Ursula', P.O. Box 422, 2260 AK Leidschendam, The Netherlands.

E-mail address: a.dingemans@centrumeetstoornissen.nl (A.E. Dingemans).
}

Only a few studies have attempted to unravel the causal relationship between depression and binge eating. Chua, Touyz, and Hill (2004) experimentally manipulated the mood of obese persons with binge eating episodes and found that participants ate more after watching a sad film (negative mood induction) than after watching a neutral film. However, in a similar mood induction experiment that compared BED-diagnosed participants with a weight-matched non-eating-disordered control group, Telch and Agras (1996) observed that while BED participants consumed significantly more calories at a multi-item buffet than control participants, food intake quantity was not affected by mood. However, acute negative mood did influence how BED participants perceived and labeled their eating episode. After a sad movie, BED participants were more likely to label their eating episode as excessive and to report more loss of control over their eating than control participants. In a later experiment the researchers (Agras \& Telch, 1998) replicated their finding that acute negative mood significantly increased the perception of loss of control over eating. Agras and Telch (1998) argued that a negative mood state lessens the sense of control over eating and therefore makes the labeling of an eating episode as a binge more likely. No differences were found in stable depressive symptoms between those who binge ate at the buffet and those who did not. Agras and Telch suggested that acute negative affect rather than a stable negative mood leads to binge eating. 
Thus to date, findings on the causal relationship between depressive symptoms, acute negative mood, and excessive eating are inconclusive. The pervasiveness however of the link between emotional distress and binge eating suggests that the question is not whether but how negative affect produces these effects (Tice, Bratslavsky, \& Baumeister, 2001).

In a previous randomized controlled trial in which the effectiveness of cognitive behavioral therapy in patients with BED was investigated (Dingemans et al., 2007), we found that less worrying about weight fully mediated abstinence of binge eating at post treatment and less worrying about shape and eating, depressive symptoms, and more general psychopathological symptoms marginally mediated abstinence. In other words, worrying was positively correlated with binge eating. It is likely that worrying and ruminating about one's weight and appearance are unpleasant experiences. Binge eating may be used as a mean to escape from these negative thoughts and worries and may in this way help to alleviate emotional stress (Heatherton \& Baumeister, 1991).

To control the urge to binge eat or to regulate negative emotions, people need to exert self-control. Self-control involves regulating or inhibiting competing urges, behaviors, and desires. Muraven and Baumeister (2000) proposed 'that people have a limited quantity of resources available for self-control and that various acts of self-control draw on this limited stock' (p. 247). Automatic processes are efficient whereas controlled ones are costly in terms of effortful consumption of resources (Muraven \& Baumeister, 2000). Controlling one's behavior requires the expenditure and depletion of a limited inner resource (Baumeister, Tice, Bratslavsky, \& Muraven, 1998). When a situation demands two consecutive acts of self-control, performance on the second (unrelated) act is frequently impaired because of energy depletion. After depletion, the resources need to be restored by means of rest and relaxation. In a study by Muraven, Tice, and Baumeister (1998), for example, participants shown an upsetting movie either received instruction to regulate their emotions (by either exaggerating or suppressing their emotional response) or received no emotion regulation instructions. Afterwards the participants had to squeeze a handgrip as long as possible, an exercise that is almost entirely a measure of self-control. Participants who had to actively regulate their emotions (exaggeration or suppression) performed worse on the subsequent handgrip-squeezing task than participants who received no such instructions. In other words, active emotion regulation undermined persistence on a next selfcontrol task because of a lack of energy.

In a similar study, Vohs and Heatherton (2001) instructed chronic female dieters either to regulate their emotional reactions by suppressing them while watching an upsetting movie or to show their natural reactions. Directly after, participants took part in an ice cream tasting task. The participants who were instructed to suppress their emotional reactions ate significantly more ice cream during the taste task than the participants who were asked to act naturally. Together these results suggest that a first exercise of self-control impairs people's performance on a subsequent, unrelated self-control task. Important to note is that in the experiments of Muraven et al. (1998) and of Vohs and Heatherton (2001), there were no differences in the extent to which participants' mood was affected by the upsetting movie fragments. As intended, all participants reported a more negative mood after watching the movie, regardless of the instructions received to suppress or exaggerate their emotions or to act naturally. Thus, participants who did or did not regulate their emotions differed only with respect to the amount of self-control exerted while watching the upsetting movie and not with respect to the extent they were emotionally affected by the movie. A well-known researcher in the field of thought and emotion suppression and who studied this in a laboratory setting, is Daniel Wegner (Wegner, 1994; Wegner, White, Schneider, \& Carter, 1987; Wenzlaff \& Wegner, 2000). His group investigated and reported on what they called the ironic effects of mental control such as thought or emotion suppression (i.e. the famous white bear studies). Studies on mental control in general and emotion suppression in particular have showed frequently and consistently that people fail when they try to suppress an emotion or negative mood. Because people engage in a suppression-induced search for target-thoughts, suppression leads to a counterproductive result in the form of intrusions of the thought one wanted to ban. Thought suppression seems to have the opposite effect and makes people fixate on it. Ample evidence exists that this is especially true for affective states (Martijn, Tenbult, Merckelbach, Dreezens, \& de Vries, 2002; Wegner, Erber, \& Zanakos, 1994). The suppression of emotionally loaded stimuli is even more difficult than neutral stimuli. When people want to stop a worry, escape bad moods or to stop thinking about food when on a diet, they fail again and again. More specifically, studies on emotion regulation and self-control ability showed that it is more likely that the regulation of emotional reactions causes loss of control (i.e. overeating) than the mere experience of negative emotions.

However, Tice et al. (2001) have suggested that emotional distress might shift priorities to the immediate present. When people feel acutely bad, they generally wish to feel better and this wish is often urgent. Certain impulses or self-indulgent behaviors are not always simply a sign of reduced control; rather, they may be strategic efforts at affect regulation. It could be argued that people with BED choose to binge on high calorie foods because it gives them immediate relief and pleasure, rather than that binge eating is a consequence of energy depletion.

The aim of the present experimental study is to investigate the causal relation between the regulation of negative emotions, negative mood, and binge eating. Participants were randomly assigned to either a condition in which they were instructed to suppress their emotional reactions during a sad film fragment or to a condition in which they had to show their natural reactions. Afterwards they were all subjected to a taste task. We hypothesized that overeating is a consequence of an attempt to regulate negative emotions because the limited store of self-control resources has been depleted by a prior act of self-control (suppression of emotional reactions). Secondly, we hypothesized that the negative mood induction would evoke a specifically increased caloric intake in depressed BED patients. Depressed individuals have lower levels of energy and hence, less resources available for self-control purposes than non-depressed individuals as pointed out by Baumeister and Exline (2000) (p. 35) or an increased caloric intake in depressed BED patients might be caused by a direct affect regulation as has been proposed by Tice et al. (2001).

\section{Method}

\section{Participants}

The participants included in this study had a primary diagnosis of (sub)threshold binge eating disorder according to DSM-IV criteria (American Psychiatric Association, 1994). To be included in the study, a participant had to report an average of one bingeeating episode a week over the previous 24 weeks. Women with a sub-threshold BED (an average of one binge eating episode a week) were included in the study because they do not seem to differ significantly from full-syndrome BED (an average of two or more binge eating episodes a week) (Striegel-Moore et al., 2000). Participants had to be female and between 18 and 60 years old. 
Pregnancy was an exclusion criterion. Subjects could participate in the study if they were stable on medication.

Participants were recruited from patients of the Center of Eating Disorders Ursula ( $n=15,23 \%$ ), by advertisements ( $n=51,77 \%$ ) in local newspapers, and via Internet websites. The Dutch Medical Ethics Committee for Mental Health Institutions approved the study.

\section{Measures}

\section{Demographic variables}

Participants' marital status, socioeconomic status (homemaker/ retired, fulltime job/student, part-time job, or disabled), educational level (low, medium, high), and age were recorded.

\section{Eating Disorder Examination (EDE)}

The Eating Disorder Examination (Cooper \& Fairburn, 1987; Jansen, 2000) is an investigator-based, semi-structured interview format for the assessment of eating disorder specific psychopathologies. The EDE assesses the state of the participant in the previous 4 weeks. It provides a comprehensive profile of individual psychopathology based on scores on four subscales: restraint (e.g. attempts to avoid certain foods), eating concern (e.g. concern about being seen while eating), shape concern (e.g. importance of body shape in self-evaluation), and weight concern (e.g. dissatisfaction with body weight). A global scale of eating pathology (computed as the mean of the participants' scores on the four subscales) is also computed to assess overall eating psychopathology. Items are rated on 7-point forced-choice scales (0-6), with higher scores reflecting greater severity or frequency. The EDE also assesses two key behavioral aspects of eating disorders: overeating and the use of extreme methods of weight control.

The inter-rater reliability was also examined in patients with BED and was excellent for objective bulimic episodes and days (correlations above .98) and very good for the EDE-subscales albeit somewhat variable (correlations range from .65 to .96) (Grilo, Masheb, Lozano-Blanco, \& Barry, 2004).

\section{Beck Depression Inventory-II (BDI-II)}

The Dutch version of the Beck Depression Inventory-II (Van der Does, 2002) contains 21 items, each with four self-evaluative statements rated on severity (scored from 0 to 3 ). The BDI-II measures severity of depressive symptoms. The total score is a simple sum of the 21 individual item scores and may range from 0 to 63 . The following guidelines are suggested as BDI cut-off scores in samples of patients diagnosed as having an affective disorder: no or minimal depression is $<13$; mild depression is $14-19$; moderate to severe depression is 20-28; and severe depression is 29-63. The internal consistency of the Dutch version of the BDI-II is high in a psychiatric outpatient group and a healthy control group: Cronbach's alpha was 0.92 and 0.88 respectively. Test-retest reliability correlation in the same groups was $r=0.82$.

\section{Mood scale}

Current mood state was measured by seven adjectives (sad, tense, tired, cheerful, active, irritated, and gloomy) on a $100 \mathrm{~mm}$ Visual Analogue Scale (VAS) on which the end points were labeled 'not at all-extremely'. The adjectives were classified into two categories: (1) mood (sad, tense, cheerful, irritated and gloomy) (Cronbach's alpha $=0.76),(2)$ fatigue (tired and active) (Cronbach's alpha $=0.56)$. Furthermore, one statement which measured overall affect ("altogether my mood at the moment is. ..") was measured on a $100 \mathrm{~mm}$ VAS on which the end points were labeled 'very goodvery bad'. A lower score indicated a more negative mood, more fatigue, and more negative affect. The mood scale was based on a mood measurement used by Martijn et al. (2002).

\section{Compliance check}

To assess compliance with the instructions while watching the film fragment, the participants had to rate three statements on a Visual Analogue Scale which was $100 \mathrm{~mm}$ long and word-anchored at each end (very untrue-very true): 'While watching the film fragment, I tried to control my emotions and feelings/I succeeded in controlling my emotions and feelings/I gave my emotions free rein'. One overall scale was made for the mean level of suppression (Cronbach's Alpha $=0.78$ ). A higher score indicated more suppression.

\section{Taste task and food intake}

During the taste task each participant was asked to take a seat behind the table with four pre-weighted bowls with large quantities of food: chocolate $(M=1025 \mathrm{~g}$ (5483 kcal), S.D. $=87 \mathrm{~g}$ $(465 \mathrm{kcal}))$, potato chips $(M=220 \mathrm{~g}(1177 \mathrm{kcal}), \quad$ S.D. $=33 \mathrm{~g}$ (177 kcal)), marshmallows $(M=258 \mathrm{~g} \quad(833 \mathrm{kcal}), \quad$ S.D. $=77 \mathrm{~g}$ (249 kcal)), and cake ( $M=638 \mathrm{~g}$ (2680 kcal), S.D. $107 \mathrm{~g}$ (449 kcal)). During the taste test they had to fill in a Taste Test Questionnaire (Guerrieri et al., 2007). Participants had to rate the four kinds of foods on palatability, intentions to eat, taste and smell. They had to fill out the questionnaire to give them a chance to consume the foods. Data were not analyzed except the item that measured how much they liked the food (ranging form 'not at all' (0) to 'very much' (5)). The total amount of food left was measured afterwards and total caloric intake was calculated. Two aspects of food intake were rated on separate $100 \mathrm{~mm}$ VAS-scales. Loss of control was evaluated by the item "Did you have control over the amount of food you ate?" and rated on a scale varying from 'completely not' to "completely'. Perceived amount of food ("How much did you eat?") was scored on a VAS-scale varying from 'not a lot' to 'a lot'. Further, participants were asked (yes/no) whether they considered their eating a binge-eating episode ("Did you feel as though you experienced a binge eating episode?").

\section{Procedures}

Respondents who reacted to the call for participants in a study on "perception and reactions of persons with binge eating episodes" were first screened by phone or email with regard to the inclusion and exclusion criteria. Potential participants $(N=111)$ were sent an information letter and a screening questionnaire. Forty-five individuals did not participate in the study because of a lack of interest $(n=38)$ or not meeting inclusion criteria $(n=7)$. In total, 66 individuals participated in the study and were invited to the Center for Eating Disorders "Ursula". All participants signed an informed consent and received a monetary reward.

Participants were instructed not to eat $2 \mathrm{~h}$ prior to the assessment and were tested individually. At their arrival they stated that they had followed instructions and had not eaten in the two hours prior to the testing. Because subjects were randomly assigned to one of the two conditions we assumed that differences in levels of hunger are equally distributed across the two conditions. They were randomly allocated to one of the two conditions: an emotion suppression condition $(n=33)$ or a "natural reaction" condition $(n=33)$. Before the start of the experiment, each participant was interviewed by means of the Eating Disorder Examination (Cooper \& Fairburn, 1987; Jansen, 2000) and filled out the Beck Depression Inventory-II (BDI-II) (Van der Does, 2002). After completion of the interview and questionnaire, the participant was seated in front of a monitor. Four bowls with food were placed on a separate table masked by a folding screen. All participants stated on the Taste Test Questionnaire that they like at least two kinds of food (score 3 or 
higher). Time of assessment was equally distributed over the two conditions.

Before the mood induction (T1) started, the participant filled out a mood scale questionnaire (see section 'Measures'). Subsequently she was given instructions about how to regulate her emotions while watching a 3-min fragment of the movie The Champ. Studies by Gross and Levenson (1995) showed that this fragment of the movie elicits sadness. Half of the participants were instructed to suppress their emotions (suppression condition) whereas the other half was instructed to react naturally (natural reaction condition).

The suppression condition received the following instruction: "In a moment you will see a fragment of a movie. This fragment may evoke emotions. Watch the fragment with attention, let in the emotions you feel and try to suppress and control your emotional reactions. In other words, if someone were present in the room with you, he or she should not see what or how you are feeling. Before the fragment starts the screen will be blank for a minute. Try to clear your mind of all thoughts and emotions. I will leave you alone while you watch the fragment and will return afterwards". The natural reaction condition received the following instruction: "In a moment you will see a fragment of a movie. This fragment may evoke emotions. Watch the fragment with attention and let in the emotions you feel and react to them as you please. Before the fragment starts the screen will be blank for a minute. Try to clear your mind of all thoughts and emotions. I will leave you alone while you watch the fragment and will return afterwards."

After each participant watched the movie fragment, her mood was measured again (T2). Subsequently she took part in the 15min taste task. She was instructed to taste all four kinds of food (see section measures) and to fill out a taste perception questionnaire. She was told to feel free to eat as much as she liked or thought was necessary to evaluate each food. During the taste task, participants were left alone in order to minimize uncomfortable or negative feelings that might arise if someone watched them eat. After the taste task, the participant filled out the mood scales again (T3), and completed a questionnaire to assess compliance with the instructions and food intake. Participants then completed a funnelled debriefing form (Bargh \& Chartrand, 2000), which checked for awareness and suspicion. None of the participants reported any awareness of the true nature of the hypothesised connection between the mood induction, suppression instructions and the taste test. At the end of the experiment the participants were fully debriefed of the real purpose of the study.

\section{Statistical analyses}

Possible pre-experimental differences in demographics and clinical variables, differences in levels of negative affect and mood during mood induction, and differences in suppression/showing emotions between the 2 conditions (natural reaction and suppression) were checked by means of independent sample $t$ tests, AN(C)OVA, or chi-square tests if appropriate. Subsequently, data to test the hypotheses were analyzed by means of linear regression analyses.

\section{Results}

\section{Participant characteristics}

Participant characteristics are displayed in Table 1 . There were no differences between the suppression condition $(n=33)$ and natural reaction condition ( $n=33$ ) with respect to demographic variables (marital status $\left(\chi^{2}\right.$ (d.f. $\left.=3\right)=1.16$, ns); socioeconomic status $\left(\chi^{2}(\right.$ d.f. $=3)=0.12$, ns $)$; education $\left(\chi^{2}(\right.$ d.f. $=3)=2.88$, ns $)$; or age $(M=39.0$, S.D. $=9.6 ; t(1,64)=0.46$, ns $))$. Ten participants used anti-depressant medication (five participants in each condition). Participants in the suppression condition reported more depressive symptoms during the previous 2 weeks (as measured by the BDI-II) than participants in the natural reactions condition. Further, the suppression condition reported a marginally significant worse mood at baseline than the natural reactions condition (see Table 1). Time of assessment was equally distributed over the two conditions.

\section{Manipulation check}

In order to test our hypotheses we first needed to establish (1) that all participants (independent of condition) became significantly sadder after the mood induction, in other words they all had to experience negative emotions and (2) that the participants who were instructed to suppress/regulate their emotional reactions did in fact suppress/regulate their emotional reactions (suppression condition) significantly more than participants who received no such instructions (natural reactions condition).

\section{Negative mood induction}

There was a significant difference in depressive symptoms (BDI) prior to the start of the film fragment between the suppression condition and the natural reactions condition (see Table 1). A 2between $\times 2$-within ANCOVA was conducted with the factors condition (suppression versus natural reactions condition) and time ( $\mathrm{T} 1$ versus $\mathrm{T} 2$ ) correcting for depressive symptoms (BDI). As expected, there was a significant main effect of time $(F(1,63)=9.22, p<.01)$, indicating that mood in both conditions became more negative after watching the upsetting movie fragment $\quad\left(M_{\text {suppression }} \mathrm{T} 1=62.6, \quad\right.$ S.D. $=19.0 ; \quad M_{\text {natural reactions }}$ T1 = 70.7, S.D. $=17.5 ; M_{\text {suppression }}$ T2 = 50.7, S.D. $=22.3$ and $M_{\text {natur- }}$ al reactions $\mathrm{T} 2=58.1$, S.D. $=19.7$; see also Fig. 1 ). The two conditions

Table 1

Baseline characteristics of natural emotions condition versus suppression condition

\begin{tabular}{|c|c|c|c|}
\hline & Natural emotions condition $(N=33)(M$, S.D. $)$ & Suppression condition $(N=33)(M$, S.D. $)$ & Test statistics and significance \\
\hline Objective binges episodes/28 days & $11.5 \pm 6.6$ & $10.3 \pm 7.6$ & $t(64)=0.67, \mathrm{~ns}$ \\
\hline Subjective binge episodes/28 days & $5.8 \pm 7.3$ & $12.3 \pm 10.0$ & $t(64)=-0.69, \mathrm{~ns}$ \\
\hline EDE Restraint & $1.68 \pm 0.99$ & $1.66 \pm 0.98$ & $t(64)=0.07, \mathrm{~ns}$ \\
\hline EDE Concern about eating & $1.34 \pm 1.07$ & $1.72 \pm 1.33$ & $t(64)=-1.28, \mathrm{~ns}$ \\
\hline EDE Concern about weight & $2.80 \pm 1.24$ & $3.28 \pm 1.31$ & $t(64)=-1.50, \mathrm{~ns}$ \\
\hline EDE Concern about figure & $2.44 \pm 1.17$ & $2.78 \pm 1.25$ & $t(64)=-1.16, \mathrm{~ns}$ \\
\hline BMI & $32.6 \pm 8.18$ & $33.8 \pm 6.48$ & $t(64)=-0.68, \mathrm{~ns}$ \\
\hline BDI (depressive symptoms) & $18.1 \pm 10.1$ & $24.0 \pm 12.4$ & $t(64)=-2.14, p=0.04$ \\
\hline Mood (VAS) baseline $(0-100 \mathrm{~mm})$ & $70.7 \pm 17.5$ & $62.6 \pm 19.0$ & $t(64)=1.82, p=0.07$ \\
\hline Fatigue (VAS) baseline $(0-100 \mathrm{~mm})$ & $51.9 \pm 23.8$ & $44.6 \pm 23.9$ & $t(64)=1.28, \mathrm{~ns}$ \\
\hline Affect (VAS) baseline $(0-100 \mathrm{~mm})$ & $62.1 \pm 22.9$ & $58.7 \pm 20.7$ & $t(64)=0.64, \mathrm{~ns}$ \\
\hline
\end{tabular}




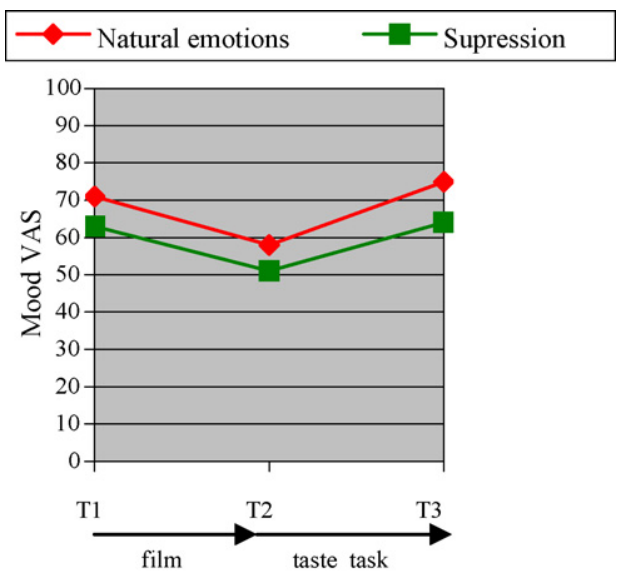

Fig. 1. Changes of mood.

did not differ in overall mood change (T1-T2). We found no interaction effect $(F(2,63)<1$, ns $)$.

The results for overall affect and fatigue were similar, that is, a significant time effect $(F(1,64)=20.5, p<.01)$ but no significant group $(F(1,64)=1.1$, ns $)$ or interaction effect $F(1,64)=0.46$, ns $)$ was found for overall affect. A significant time effect $(F(1,64)=4.04$, $p=0.05$ ) was also found for fatigue, but no significant group $(F(1,64)=2.19$, ns $)$ or interaction effect $(F(1,64)<1$, ns $)$.

Thus we conclude that the film fragment had the intended effect of inducing an equally negative mood state in both conditions.

\section{Compliance with instructions}

We checked whether participants in the suppression condition followed our instructions and tried to control their emotional response towards the film fragment more than participants in the natural reaction condition. On the VAS-suppression scale the participants in the suppression condition had a mean score of 79.5 (S.D. = 13.8) and the natural reactions condition a mean score of 57.1 (S.D. $=27.8$ ). A $t$-test was conducted with condition (suppression versus natural reactions condition) as the independent variable and degree of suppression as the dependent variable. A significant effect was found between the degree of reported suppression of emotional reactions in the two conditions $(t(63)=4.13, p<.001)$. As expected, participants in the suppression condition tried to suppress and control their emotions more than participants in the natural reactions condition. The participants had complied with our instructions.

\section{Effects of mood suppression on food intake}

In order to test the first hypothesis about the effect of suppression of negative emotional reactions on caloric intake, we conducted a stepwise linear regression analysis with caloric intake as dependent variable and condition (suppression versus natural reactions) as main predictor while controlling for depressive symptoms (BDI-II score), mood at T1 (VAS), and BMI as possible confounders.

Our prediction was not confirmed: participants in the suppression condition ( $M=455 \mathrm{kcal}$, S.D. 312$)$, did not eat more during the taste task than participants in the natural reactions condition ( $M=461 \mathrm{kcal}$, S.D. 206) $(\beta=-37.84, t(65)=0.59$, ns $)$.

\section{The effect of suppression and depression on caloric intake}

In order to test our second hypothesis that the level of depressive symptoms (as measured by the BDI-II) would exaggerate caloric intake differences in the two conditions, we added an interaction term (BDI-II $\mathrm{x}$ condition) to the equation. It was hypothesized that the negative mood induction would elicit increased calorie intake in depressed BED participants in the suppression condition. No interaction effect of condition and level of depression was found $(\beta=6.67, t(65)=1.17$, ns). We tested whether mood changes during the taste task had a different effect on caloric intake in the two conditions. No interaction effect was found, after correcting for depressive symptoms ( $\beta=17.7$, $t(1,65)=0.71$, ns). Overall, mood tended to improve during the taste task (T2-T3) independent of the condition $(F(1,64)=34.98$, $p<0.001$ ) (see Fig. 1).

\section{The effect of depression on caloric intake}

The level of depressive symptoms (BDI-II) predicted caloric intake independent of condition (suppression or natural reactions) (correcting for BMI and mood at T1) $(\beta=9.96, t(1,65)=3.3$, $p=.002$ ). Because of this previous finding, we tested whether depressed BED participants behaved different than non-depressed BED participants during the mood induction and the taste task.

We tested whether changes in mood during the mood induction (T1-T2) had an effect on caloric intake. For this analysis, we first calculated individual mood change scores by subtracting the first measurement at the very beginning of the experiment (T1) from the mood measurement after the mood induction (T2). These mood change scores (T1-T2), depressive symptoms (BDI-II), and their interaction were entered into the equation with caloric intake as the dependent variable correcting for condition. There was a significant interaction effect of depressive symptoms and mood change during the film $(\beta=-2.80, t(1,65)=2.17, p=.03)$. The more depressed BED participants were and the more their mood worsened during the mood induction, the more calories they consumed.

Next, we tested whether mood changes during the taste task had an effect on caloric intake. Mood change scores (T2-T3) were calculated by subtracting the mood score at the beginning of the taste task (T2) from the mood measurement at the end of the taste task (T3). Depressive symptoms (BDI-II), mood changes (T2-T3), and their interaction term were entered into the equation with caloric intake as dependent variable. Again a significant interaction effect was found between depressive symptoms and mood change during the taste task $(\beta=3.11, t(65)=2.84, p<.01)$. Depressed BED participants who consumed more calories during the taste task experienced more positive mood changes than less depressed BED participants.

In order to further examine the effect of depression, caloric intake, and mood change, the total group was divided by means of the BDI-II (Van der Does, 2002) into a moderately to severely depressed group ( $n=36$; BDI-II score 20 or higher; $M=29.4$, S.D. 7.6), and a non- to mildly depressed group ( $n=30$; BDI-II score between 0 and 19; $M=11.0$, S.D. 6.2). We tested within the "non to mildly"-depressed group and the "moderate to severe" depressed group separately, whether the changes in mood during the mood induction (T1-T2) and the changes in mood during the taste task (T2-T3), influenced caloric intake. A positive linear relation was found between caloric intake and mood changes during the mood induction $(\beta=-78.73, t(1,34)=2.89, p<.01)$ and also between caloric intake and mood change during the taste task $(\beta=70.03$, $t(1,34)=3.2, p<.01)$ in the group with high depressive symptoms (see Fig. 2). Correcting for condition (suppression versus natural emotions) and baseline mood score (VAS) did not change the results. In general, participants' mood was negatively affected by the film and returned to baseline after the taste task. Within the depressive group, those depressed participants who experienced 

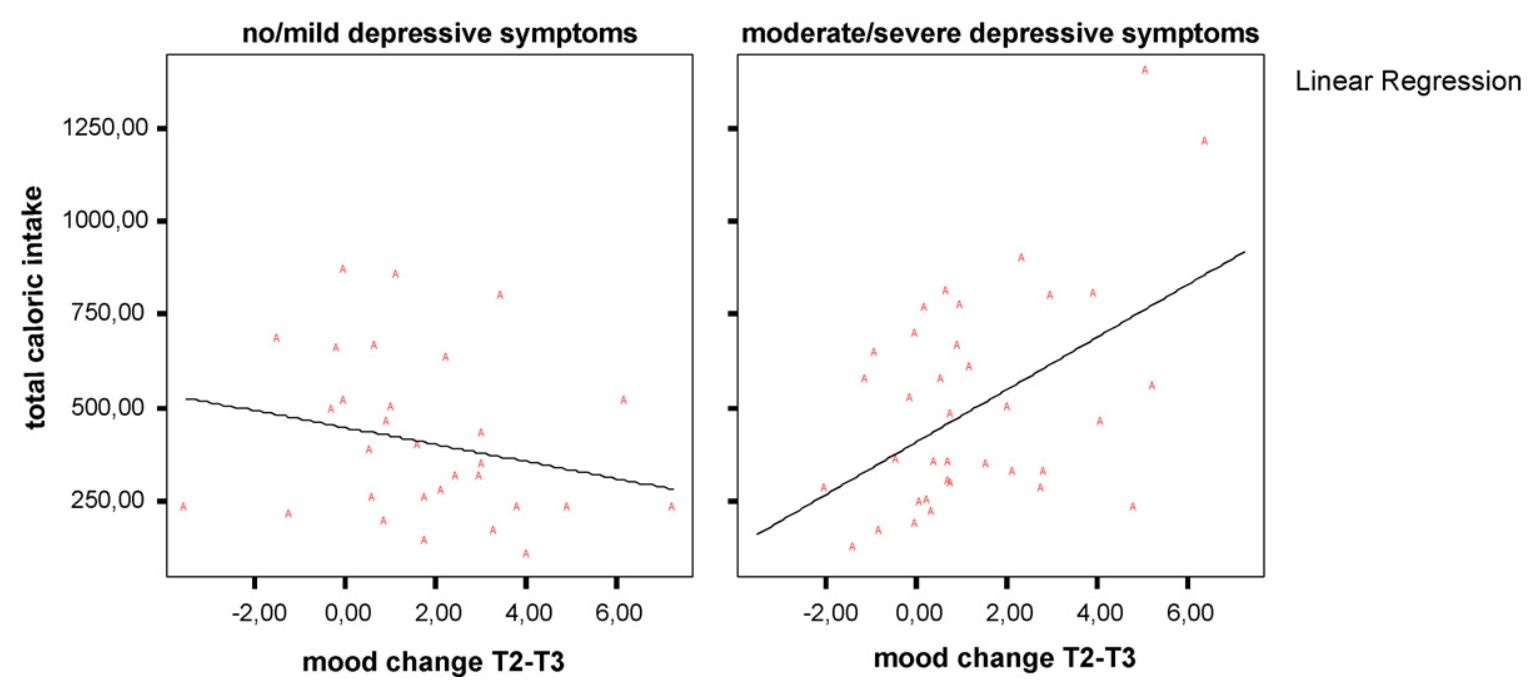

Fig. 2. Linear regression with total caloric intake as dependent variable and mood changes during taste task (T2T3) as the independent variable.

the greatest mood shift also tended to eat the most and those who experienced the smallest mood shift tended to eat the least. In contrast, within the group with no or mild depressive symptoms, caloric intake was unrelated to the extent of mood changes from the mood induction $(\beta=28.04, t(1,28)=1.41, p=.17$, ns $)$ and the taste task $(\beta=-22.72, t(1,28)=0.24, p=.21$, ns) (see Fig. 2). Results also did not change after controlling for condition and BMI.

Finally, we tested in two separate regression analyses whether perceived loss of control over eating and the perceived food intake could be predicted by severity of depressive symptoms by correcting for condition and the actual caloric intake. The main finding was that the perceived loss of control and perceived food intake were explained by actual caloric intake $(\beta=-.62$, $t(3,61)=-5.92, \quad p<.01$ and $\beta=-.61, t(3,61)=-5.96, p<.01$, resp.) and not influenced by the severity of depressive symptoms ('no-mild'-depressed versus 'moderate-severe' depressed) $(\beta=-.025, t(3,61)<1$, ns and $\beta=.13, t(3,61)=1.24$, ns, respectively).

\section{Discussion}

The present study examined the role of negative emotions on binge eating in individuals with binge eating disorder. The first aim was to investigate whether binge eating is a consequence of regulating one's negative emotions. We hypothesized that a limited inner source of self-control is depleted after a first act of self-control, i.e. regulating one's emotions. The results did not support this expectation: BED participants who attempted to suppress their emotions while watching an upsetting movie did not consume more calories in a subsequent taste task compared to those who did not suppress their emotions. It could be argued that the participants in the suppression condition did not suppress their emotions enough to deplete their inner resources. However, our manipulation check indicated that participants in the suppression condition attempted to suppress their emotions significantly more than participants in the natural reactions condition.

Our second hypothesis was that suppression of negative emotional reactions would induce greater calorie intake in depressed BED participants. We hypothesized that severely depressed BED participants have fewer resources available to regulate their negative mood effectively (Baumeister \& Exline, 2000). No interaction effect was found between depressive symptoms and condition (suppression versus natural reactions).
Suppression of negative emotional reactions in the moderately to severely depressed group did not lead to more caloric intake compared to suppression in the not to mildly depressed group. Our results thus showed that there is a positive association between depressive symptoms and caloric intake irrespective of condition (suppression versus natural reactions).

It might be hypothesized that overeating is related to an immediate repair of negative mood. Sad people often indulge in fattening snacks because, as Tice et al. (2001) concluded in their study, they believe that eating repairs their mood. Continuous attempts to control one self are strongly guided by people's expectations and cognitions about how self-control works (Martijn et al., 2002). They expect that fattening foods will improve their mood. People tend to abandon or violate their normal selfregulatory efforts (control over eating) because they give priority to affect regulation.

Individuals with BED who had severe depressive symptoms consumed more calories than individuals who had no or mild depressive symptoms. Furthermore, within the severely depressed group, those participants who experienced more negative mood change during the film fragment (manipulation) and those who reported more positive mood change during the taste task, had a higher caloric intake (not related to experimental condition (suppression or natural reactions)). From these data one might conclude that depressed BED participants seek to regulate acute negative states, an inclination which the availability of high calorie food reinforces.

In contrast, caloric intake in the group with no or mild depressive symptoms was unrelated to mood changes during either the mood induction or the taste task. Why did we not find a correlation between mood changes and caloric intake in the nondepressed group? Individuals with BED and moderate-to-severe depressive symptoms might have less adequate coping strategies to regulate acute mood changes than those without a depression. The extent to which individuals believe that they can effectively cope with negative moods might play a role in the initiation and maintenance of eating disorder symptomatology. Depressed people (with BED) are less able to cope with negative moods and are therefore more likely to engage in ineffective coping strategies such as binge eating. Depressive symptoms such as increased appetite, hopelessness or feeling of failure may also contribute to increased caloric intake (Presnell, Stice, \& Tristan, 2008). Non-depressed subjects with BED only have to regulate the 
temporal negative mood swings and stop eating when they feel better. Depressed subjects still feel gloomy or sad after regulating the negative mood dip and therefore tend to eat more and/or longer. Notable is that fact that the sense of loss of control is not related to depression. Feelings of loss of control and perceived caloric intake are both positively related to actual intake.

In our study mood worsened as a result of the mood induction and returned back to baseline after the taste test. It could be argued that the restoration of mood after the taste test was a natural consequence of time and is not attributable to eating. However, our interpretation that overeating serves as a means to repair one's negative mood is in accordance with several other studies which have also found that (binge) eating (temporarily) decreases the level of negative emotions (Deaver, Meidinger, Crosby, Miltenberger, \& Smyth, 2003; Macht \& Mueller, 2007; Munsch, Meyer, Margraf, Michael, \& Biedert, 2008). Affect is reported to change over the course of binge eating. Eating makes binge eaters feel better, at least in the short run, or it softens their negative emotions (McManus \& Waller, 1995; Heatherton \& Baumeister, 1991). A hypothesis for a next study is thus that the specific expectation of mood improvement by the consumption of high calorie food leads to overeating.

In clinical practice, therapists should pay attention to patients with BED and severe depressive symptoms especially those who experience large mood swings. These patients tend to eat larger amounts of food during binge eating episodes and are therefore more prone to become (more) obese. Also, extra treatment could be offered for the depressive symptoms for example by means of anti-depressant medication or psychotherapy directed at the depression. It might be useful to learn more adaptive affect regulation skills.

In summary, our main findings were that in individuals with BED, the initial mood before watching the movie was restored after eating. Overeating might serve as a means to repair one's negative mood. Furthermore, more severe depressive symptomatology was correlated with a higher caloric intake. Moreover, within the group of BED participants with moderate-to-severe depressive symptoms, a higher caloric intake was observed for those who were most affected by the negative mood induction. This correlation was not found in the non-depressed BED group. The hypothesis that suppression of negative emotional reactions would lead to overeating in binge eaters was not supported.

\section{References}

Agras, W. S., \& Telch, C. F. (1998). The effects of caloric deprivation and negative affect on binge eating in obese binge-eating disordered women. Behavior Therapy, 29, 491 503.

American Psychiatric Association. (1994). Diagnostic and statistical manual of menta disorders, fourth edition DSM-IV. Washington DC: American Psychiatric Association.

Bargh, J., \& Chartrand, T. (2000). The mind in the middle: a practical guide to priming and automaticity research. In H. Reis \& C. Judd (Eds.), Handbook of research methods in social and personality psychology (pp. 253-285). Cambridge, UK: Cambridge University Press.

Baumeister, R. F., \& Exline, J. J. (2000). Self-control, morality, and human strength. Journal of Social and Clinical Psychology, 19, 29-42.

Baumeister, R. F., Tice, D. M., Bratslavsky, E., \& Muraven, M. (1998). Ego depletion: is the active self a limited resource? Journal of Personality And Social Psychology, 74, 12521265.
Chua, J. L., Touyz, S., \& Hill, A. J. (2004). Negative mood-induced overeating in obese binge eaters: an experimental study. International Journal of Obesity E Related Metabolic Disorders, 28, 606-610.

Cooper, Z., \& Fairburn, C. G. (1987). The Eating Disorder Examination: a semi-structured interview for the assessment of the specific psychopathology of eating disorders. International Journal of Eating Disorders, 6, 1-8.

Crowther, J. H., Shepherd, K. L., Sanftner, J., \& Bonifazi, D. Z. (2001). The role of daily hassles in binge eating. International Journal of Eating Disorders, 29, 449-454.

Deaver, C. M., Meidinger, A., Crosby, R., Miltenberger, R. G., \& Smyth, J. (2003). An evaluation of affect and binge eating. Behavior Modification, 27, 578-599.

Dingemans, A. E., Spinhoven, P., \& Van Furth, E. F. (2007). Predictors and mediators of treatment outcome in patients with binge eating disorder. Behaviour Research And Therapy, 45, 2551-2562.

Grilo, C. M., Masheb, R. M., Lozano-Blanco, C., \& Barry, D. T. (2004). Reliability of the Eating Disorder Examination in patients with binge eating disorder. International Journal of Eating Disorders, 35, 80.

Grilo, C. M., \& Shiffman, S. (1994). Longitudinal investigation of the abstinence violation effect in binge eaters. Journal of Consulting and Clinical Psychology, 62, 611-619.

Gross, J. J., \& Levenson, R. W. (1995). Emotion elicitation using films. Cognition $\mathcal{E}$ Emotion, 9, 87-108.

Guerrieri, R., Nederkoorn, C., Stankiewicz, K., Alberts, H., Geschwind, N., Martijn, C., et al. (2007). The influence of trait and induced state impulsivity on food intake in normal-weight healthy women. Appetite, 49, 66-73.

Heatherton, T. F., \& Baumeister, R. F. (1991). Binge eating as escape from selfawareness. Psychological Bulletin, 110, 86-108.

Jansen, A. (2000). Eating Disorder Examination (EDE 12.0). Interview ter vaststelling van de specifieke psychopathologie van eetstoornissen. Lisse: Swets \& Zeitlinger.

Macht, M., \& Mueller, J. (2007). Immediate effects of chocolate on experimentally induced mood states. Appetite, 49, 667-674

Martijn, C., Tenbult, P., Merckelbach, H., Dreezens, E., \& de Vries, N. K. (2002). Getting a grip on ourselves: challenging expectancies about loss of energy after self-control. Social Cognition, 20, 441-458.

McManus, F., \& Waller, G. (1995). A functional analysis of binge-eating. Clinical Psychology Review, 15, 845-863.

Munsch, S., Meyer, A. H., Margraf, J., Michael, T., \& Biedert, E. (2008). Negative mood induction and unbalanced nutrition style as possible triggers of binges in binge eating disorder (BED). Eating and Weight Disorders, 13, 22-29.

Muraven, M., \& Baumeister, R. F. (2000). Self-regulation and depletion of limited resources: does self-control resemble a muscle? Psychological Bulletin, 126, 247259.

Muraven, M., Tice, D. M., \& Baumeister, R. F. (1998). Self-control as limited resource: regulatory depletion patterns. Journal of Personality And Social Psychology, 74, 774789

Presnell, K., Stice, E., \& Tristan, J. (2008). Experimental investigation of the effects of naturalistic dieting on bulimic symptoms: moderating effects of depressive symptoms. Appetite, 50, 91-101.

Striegel-Moore, R. H., Dohm, F. A., Solomon, R. A., Fairburn, C. G., Pike, K. M., \& Wilfley, D. E. (2000). Subthreshold binge eating disorder. International Journal of Eating Disorders, 27, 270-278.

Telch, C. F., \& Agras, W. S. (1994). Obesity, binge eating and psychopathology: are they related? International Journal of Eating Disorders, 15, 53-61.

Telch, C. F., \& Agras, W. S. (1996). Do emotional states influence binge eating in the obese? International Journal of Eating Disorders, 20, 271-279.

Tice, D. M., Bratslavsky, E., \& Baumeister, R. F. (2001). Emotional distress regulation takes precedence over impulse control: if you feel bad, do it! Journal of Personality And Social Psychology, 80, 53-67.

Van der Does, A. J. (2002). Beck Depression Inventory-II (BDI-II-NL). Lisse: Swets \& Zeitlinger

Vohs, K. D., \& Heatherton, T. F. (2001). Self-regulatory failure: a resource-depletion approach. Psychological Science, 11, 249-254.

Waters, A., Hill, A., \& Waller, G. (2001). Bulimics' responses to food cravings: is bingeeating a product of hunger or emotional state? Behaviour Research And Therapy, 39, 877-886.

Wegner, D. M. (1994). Ironic processes of mental control. Psychological Review, 101.

Wegner, D. M., Erber, R., \& Zanakos, S. (1994). Ironic processes in the mental control of mood and mood-related thought. Journal of Personality And Social Psychology, 65, 1093-1104.

Wegner, D. M., White, T. L., Schneider, D. J., \& Carter, S. R. (1987). Paradoxical effects of thought suppression. Journal of Personality And Social Psychology, 53, 5-13.

Wenzlaff, R. M., \& Wegner, D. M. (2000). Thought suppression. Annual Review Psychology, 51, 59-91. 